\title{
Heat pump in a new modular configuration to recover low-grade heat emissions at enterprises
}

\author{
Altai Sh. Alimgazin ${ }^{1}$, Saule G. Alimgazina², and Mikhail G. Zhumagulov1,* \\ ${ }^{1}$ L.N. Gumilyov Eurasian National University, Dept. of Power engineering, 2 Satpayev str, 010003 Nur-Sultan, Kazakhstan \\ ${ }^{2}$ Startup company BMHU LLP, 13 Kazhymukan str, 010008 Nur-Sultan, Kazakhstan
}

\begin{abstract}
This paper reviews application of energy-saving heat pump technologies using non-traditional and renewable energy sources (NRES) to improve the efficiency of industrial equipment, heat supply systems in public sector and in agroindustrial industry in the Republic of Kazakhstan. The heat pump technology to transform low-grade heat of secondary low-temperature power resources into high-grade heat energy suitable for practical use is not a regular upgrade of traditional power resources but introduction a new, advanced, high-efficient and ecofriendly heat generation method. Introducing Modular Heat Pumps (MHP) at metallurgic and other industrial enterprises (power industry, petrochemsitry, machinery and etc.) as well as agroindustrial complex, housing and public utilities, and state-funded organizations of the Republic of Kazakhstan is expected to get a significant economic and ecological effects, foremost, by replacing traditional heat sources (solid and liquid fuel boilers, electric boilers), decrease greenhouse gases emissions into the atmosphere, and improving ecological situation. MHP application will allow to get 2-4 times saving budget funds annually allotted for heat supply (procurement various fuel types, repair current boiler equipment, ecological payments and etc.) in comparison with the existing traditional boilers.
\end{abstract}

\section{Introduction}

One of perspective ways in energy saving and energy efficiency enhancement of the existing equipment at the Republic of Kazakhstan's enterprises is recycling lowtemperature waste heat of process water-supply systems (WSS) at power, ferrous and non-ferrous metallurgy, and oil and chemistry [1 -14, 16-18, 20-23].

Introducing MHP at metallurgic and other industrial enterprises (power industry, petrochemsitry, machinery and etc.) as well as agroindustrial complex, housing and public utilities, and state-funded organizations of the Republic of Kazakhstan is expected to get a significant economic and ecological effects, foremost, by replacing traditional heat sources (solid and liquid fuel boilers, electric boilers), decrease greenhouse gases emissions into the atmosphere [2, 3, 5-7, 12-14, 20-23].

Application heat pump technologies at the mentioned above enterprises will allow to recover considerable volume of irrevocable lost heat into the heat supply system at enterprises without additional combustion of ordinary fuel that will allow to get a significant economic effect, refuse from sometimes from purchased energy outside, thereby reducing heat combustion of entertainment.

It should be noted that prime cost of the own heat pump heat from twice to four times will be less than purchased heat, i.e.after start heat pump plant up a real opportunity to provide an existing necessity in heat energy is appeared.
As the known experience of the world leaders in a regular use of heat pump technologies (Finland, Sweden, Japan, China, Russia and others) shows a number of projects have already implemented using HP at Power Plant [2- 4, 9 -12, 14].

\subsection{Examples}

As an illustrative example of the HP application efficiency at stations let us give the data on some objects in the PRC [9-14].

Chinese power plant in Shentu

The efficiency of modern coal power plants with steam turbines is from $40 \%$ to $45 \%$, which means that about $55 \%-60 \%$ of the fuel in the form of energy that enters the power station is discharged through condensers into the atmosphere.

The key element of heating system is the heat pump which extracts a low-grade heat from cooling water after the condenser and transfers it to the hot water heating circuit (see Fig. 1.2).

After pass through the heat pump the cooling water cools down from approximately $30^{\circ} \mathrm{C}$ to $26^{\circ} \mathrm{C}$ and also enters the cooling towers. As a result of the fact that the water temperature has become lower it will be less evaporated into the atmosphere. Consequently, the consumption of additional water per cycle will be decreased.

Hot water is heated to $75^{\circ} \mathrm{C}$ in heat pumps, the final heating to $130^{\circ} \mathrm{C}$ occurs in network heaters.

\footnotetext{
* Corresponding author: mixailgng@gmail.com
} 


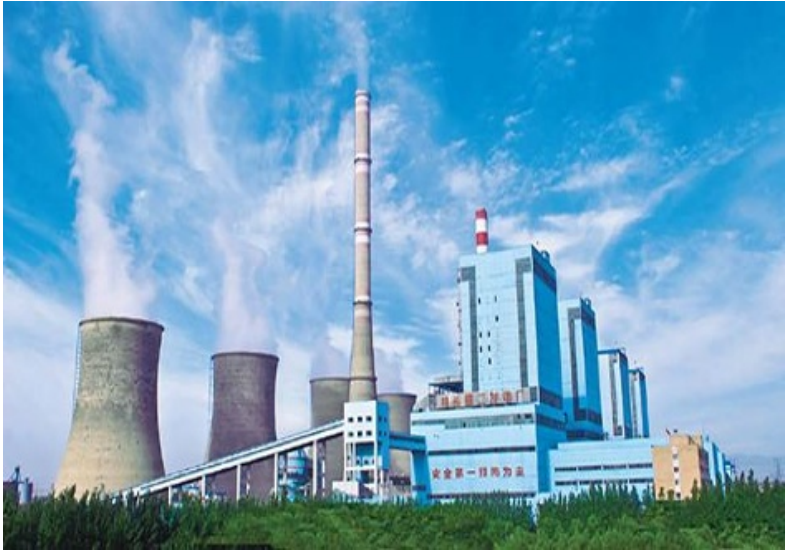

Fig. 1. Power Plant in Shentu.

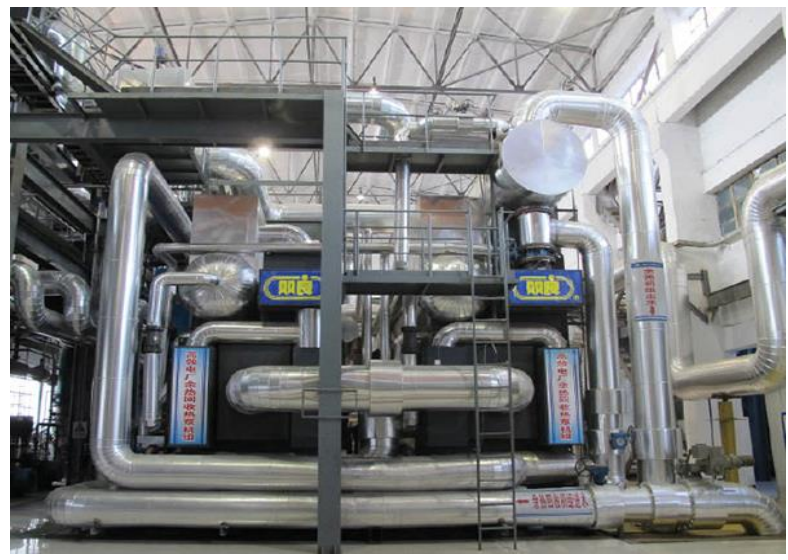

Fig. 2. TPP Assembly view.

As a result of the work carried out (2011-2014), the efficiency of station itself was significantly increased and environmental situation in the city and region as a whole was significantly improved. It is estimated that for $1 \mathrm{MW}$ of heat energy supplied from the Shentu station approximately $0.3 \mathrm{MW}$ is taken from cooling water after the condenser.

Another example of project execution with HPP

Six HPP with 30 MW capacity each from Shuangliang were installed at the power station in Yangjin (China) in 2010.

They recycle the heat energy of cooling towers (temperature $30-40^{\circ} \mathrm{C}$ ), and produce hot water with parameters $70-90^{\circ} \mathrm{C}$ for additional heat supply to the whole district of the city utilizing the heat previously discharged by the cooling towers.

HPP introduction in this project annually allowed to:

- sell additionally heat energy to the amount more than $\$ 5$ million (and tariffs for heat energy in this city are lower than in Kazakhstan);

- save 500000 tons of water (it is not evaporated in cooling towers);

- save 49300 tons of coal;

- reduce $\mathrm{CO}_{2}$ emissions by 98600 tons;

- reduce nitrogen oxide emissions by 730 tons.

The payback period for introduction HPP and use a low-temperature waste heat for heating the enterprise was less than two years.
However, there are no for a while any precedents in practical use of heat pumps (hereinafter - HP) at power enterprises (power stations, regional hydroelectric power stations) in the Republic of Kazakhstan. There are single examples of heat pumps application using waste heat at only one metallurgical enterprise Kazzinc JSC (UstKamenogorsk, 2000) [15, 20, 22].

\section{The research Object and research methods}

Starting from 2000, the scientists from Kazakhstan and Russia (MEI, Moscow, Energiya CJSC, Novosibirsk) have been carrying out joint works developing application methods and technologies for HP using waste heat of technical water-supply systems (TWSS) at industrial enterprises (metallurgic complexes, power station, oil processing plants and etc.) to improve heatpower equipment efficiency of the aforesaid enterprises $[15,20]$.

During 2005-2019 Kazakhstani scientists have been conducting research on the prospects to use heat pumps (HP) using waste heat of circulating and direct-flow water cycles of a number of real industrial facilities TETS-2 JSC in Astana, Ekibastuz TPP-2 LLP, Petropavlovsk TPP-2, SevKazEnergo JSC, UstKamenogorsk TPP LLP, Sogrinsk TPP LLP, Aluminum of Kazakhstan JSC, Arselor Mittal Temirtau JSC, Pavlodar oil chemistry Plant LLP, PS KSP Steel LLP (Pavlodar).

The important precondition to use new generation MHP at mentioned above enterprises is quite large volumes of heat discharged with circulating water into cooling towers, cooling ponds, and rivers (Irtysh and etc.) $[19,21,22]$.

Together with Russian scientists (Energiya CJSC, Novosibirsk) based on grants of the Ministry of Education and Science of the Republic of Kazakhstan (2012 - 2015) some research activities have been carried out $[15,20]$ according to results of which for the first time ever a multistage application technology was developed for the new generation HP operating at a more effective thermodynamic Lorenz cycle compared with reverse Carnot cycle and providing coolant delivery into the heat system with temperature up to $85^{\circ} \mathrm{C}$ (but not 55$62^{\circ} \mathrm{C}$ as other types of HP produced worldwide).

This unique technology was patented both in Russia and in the Republic of Kazakhstan and is ready to be practically implemented $[12,15]$.

The said technology having passed a multilevel selection in the Ministry of Energy, Ministry of Education and Science of the Republic of Kazakhstan in 2016-2017 was represented at the Sphere National booth (Kazakhstan) during the International exhibition EXPO2017 among the 25 best scientific projects of the national scientists [21].

During some research activities carried out in 20102016 based on scientific and research activities supported by the national and business contracts for commercial purposes a certain result was presented, i.e. 
a sample of a new product that is a modular heat plant (MHP) [19, 21] (see Fig.3).

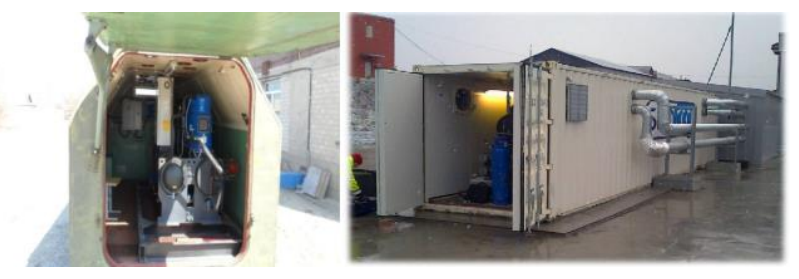

Fig. 3. General assembly of modular heat pump (MHP).

MHP being a separate stage of multistage heat pump is a metallic heat-insulated container with supporting frame. The guards are made as three-layed panels consisting of profile sheets with insulants of mineralwool boards.

All the necessary main and ancillary equipment and instrumentation will be installed inside MHP with only 4 outside pipelines for input a low-grade coolant (waste water from circulation water supply system) and output of hot water with temperature of $75-80^{\circ} \mathrm{C}$ into heat supply system of enterprise.

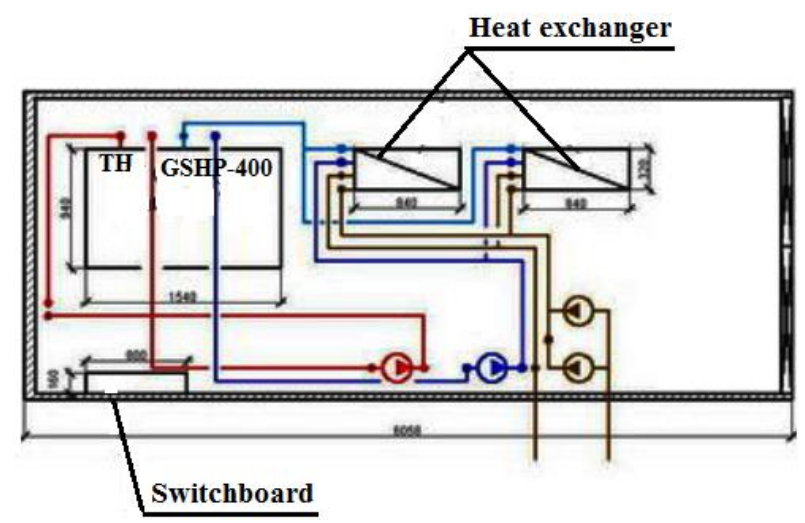

Fig. 4. Demonstrates a pilot MHP with heat capacity $400 \mathrm{~kW}$.

Supply of various modular heat pump capacities (from $200 \mathrm{~kW}$ to $2000 \mathrm{~kW}$ ) is planning to customers. The proposed container-type MHP $[19,21]$ is designed as a standard element of enterprise heat circuit ready for practical implementation at any enterprise and is planned to be used both at industrial enterprises and state-funded organizations, housing and public utilities where various alternative energy sources are available.

MHP advantages:

- a singular patented technology and multi-stage MTU application scheme ready to be practically implemented at enterprises using alternative energy sources in various regions of the country;

- adaptability of the proposed technology to severe climate conditions of the Republic of Kazakhstan (up to $\left.-40^{\circ} \mathrm{C}\right)$;

- portable and versatile (can be used in different industrial sectors where circulation water supply system is available in process cycles);

- in comparison with other existing world heat plant technologies the proposed project provides more effective power (SOR) and economical characteristics (production cost for 1 Gcal of heat, specific fuel costs when replacing traditional heat sources.

- a lower market price of our products compared to peers;

The market price for a unit of production and (or) services of this competitor can be estimated as follows.

The cost of MTU proposed (heat power up to $2 \mathrm{MW}$ ) is significantly lower than the cost of heat pumps (HP) of the equal power to foreign manufacturing companies (Germany, Sweden and etc.). The approximate cost of MTU heat power equal to $1 \mathrm{Gcal} /$ hour is about $200-220$ thousand US dollars (in comparison with foreign heat pumps of the equal heat power are about 350-440 thousand US dollars);

- high-quality warranty and after-sales service of MTU installed at enterprises;

- 80\% Kazakhstani content of the project (equipment is in modular configuration, technology, design, a complex of installation and commissioning works, highly qualified scientific and engineering personnel).

In 2017-2020, under the grant funding of the Science Fund JSC of the Ministry of Education and Science of the Republic of Kazakhstan, the scientists of the L.N. Gumilyov Eurasian National University and specialists from the start-up company BMTU LLP (Astana) have implemented a "Project oriented to commercialize modular heat pump to recover a low-potential waste heat obtained from industrial water supply systems at enterprises" at the pilot facility - pipe rolling production of a large metallurgical enterprise in the country Pavlodar Subsidiary(hereinafter referred to as PS) KSP Steel LLP (see Fig.6-7) [19, 22].

This article describes commercialization aspects of a new MHP with heat capacity $400 \mathrm{~kW}$ for lowtemperature heat waste recovery from technological processes at enterprises (enterprise waste water, water from technical water-supply system (TWSS) and etc.) to reduce emissions of hazardous substances into the atmosphere and in parallel get a high-grade heat at a certain metallurgic enterprise - PS KSP Steel LLP).

This survey explores the following issues:

- development MTU application diagram as a typical element of heat supply system at pipe rolling production (hereinafter referred to as PRP) of PS KSP Steel LLP.
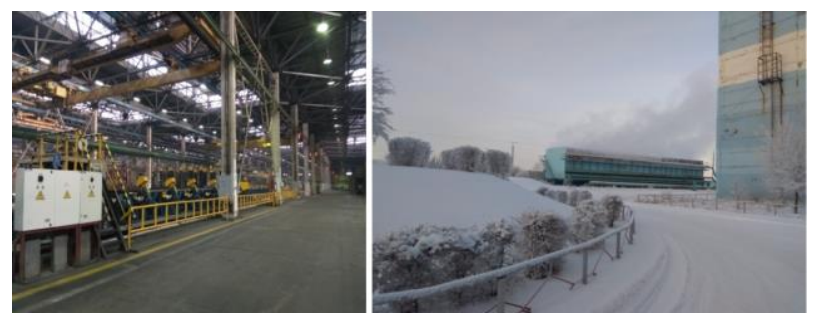

Fig. 5. General view of pipe rolling production at PS KSP Steel LLP and ventilator cooling tower of circulation water supply system.

- conducting a series of pilot tests of new equipment to determine optimal operating conditions for new generation heat pump technology when MTU prototype is included in the theat circuit of PRP KSP Steel LLP; 
- analysis of energy, environmental and economic efficiency of MTU application to recover waste heat of technical water supply system (TWS) of PRP and heat generation for heating and hot water supply of the enterprise.

At the moment, the existing power supply diagram of PS KSP Steel LLP is based on purchased heat and electric energy from TPP -3 (Pavlodar) (steam, hot water). The enterprise annually spends great funds to purchase heat power (about $46 \mathrm{Gcal} /$ hour) and electric power (about $6.5 \mathrm{mln}$ USD (data of March, 2015)).

Moreover, the current fan cooling towers used in circulation water supply system (CWSS) at the enterprise emit large volumes of heat energy into the atmosphere (according to our assessments, about 280$600 \mathrm{Gcal} / \mathrm{hour}$ ), and costs enterprise spent to purchase electric power for towers operation are substantial.

However, physical heat of water circulation systems emitted into the atmosphere through the towers is irrevocably lost which is economically inadvisable.

Besides, getting substantial volumes of own heat with temperature up to $60-85^{\circ} \mathrm{C}$ using MHP will give a chance to save large volumes of power purchased at the moment at TPP-3 (Pavlodar) to provide continuous tower fans operation.

The following table shows results of economical effect estimation from MHP implementation for hot water supply at KSP Steel LLP Pipe Rolling Plant[22].

Table 1. Comparison of annual operational costs at Pipe Rolling Production for hot water supply from various heat resources (heat load - 2 Gcal/hour).

\begin{tabular}{|c|l|c|c|}
\hline No & Heat source & $\begin{array}{c}\text { Cost per annum } \\
\text { operating costs, } \\
\text { th. KZT (th. } \\
\text { USD) }\end{array}$ & $\begin{array}{c}\text { Heat Cost, } \\
\text { KZT/Gcal } \\
\text { (USD/ Gcal) }\end{array}$ \\
\hline 1 & $\begin{array}{l}\text { Central heating } \\
\text { (from TPP-3 of } \\
\text { Pavlodar) }\end{array}$ & $72180(195)$ & $3313.8(9)$ \\
\hline 2 & $\begin{array}{l}\text { Heat pump boiler } \\
\text { room based on } \\
\text { MHP }\end{array}$ & $13160(35)$ & $751.14(2)$ \\
\hline
\end{tabular}

Thus, the results of preliminary survey give the reason to conclude that when introducing energy-saving heat pump technologies based on MHP using alternative heat sources a deeper cooling of circulating water is achieved at the KSP Steel LLP and costs to purchase heat and power from CHPP-3 in Pavlodar are reduced at the enterprise.

The source of project profitability when introducing MHP at enterprises are:

1. Remarkable economical effect, i.e. difference between heat cost the consumers purchased at CHPP and the heat generated using heat pumps (2-4 times).

2. Considerable enterprise OPEX reduction using circulating and in-line water-supply system.

3. Reduction of enterprise greenhouse emissions and ecological payments decrease consequently.

Based on the results of pilot research on MHP operation in real production conditions an analysis of power, environmental and economic efficiency of its application to recover waste heat from recycling water supply system at enterprises of the country will be carried out, specific recommendations for the further commercialization of this "green" technology at various facilities in the Republic of Kazakhstan be proposed.

In years ahead MHP of different capacities introduction is expected. It will be introduced at various enterprises of ferrous and non-ferrous metallurgy, power industry, oil and chemical industry and etc. with existing TWS (cooling towers, cooling ponds, water reservoirs.).

In particular, during 2018-2019 a research "Improving energy efficiency of metallurgical equipment at the Aksu Ferroalloy Plant (AFP) which is branch of Kazchrome TNK JSC by introducing power saving heat pump technologies recovering waste heat from circulating water supply system (Aksu, Pavlodar region)" has begun [23].

\section{Conclusion}

Thus, the following conclusions can be made.

1. Heat pump technology to transform low-grade natural heat of secondary low-temperature energy resources into high-grade heat energy for practical use is not another upgrade of traditional energy resources but implementation of a new, advanced, high-efficient and ecofriendly method of heat generation.

2. Application a technology and new generation MHP adapted to operation in cold climate conditions of Kazakhstan (up to $-45^{\circ} \mathrm{C}$ ) using discharged water heat from service water system (SWS) as a low-grade source, are perspective to introduce at existing 57 TPPs, several GRES, and a serie of ferrous and non-ferrous metallurgy, oil and chemistry industry, machinery plants and etc. that will allow to improve efficiency of heat-power equipment thereof, save budget funds, boost heat generating capacities while not increasing consumption of primary fuel (coal, residual fuel oil), reduce greenhouse emissions into the atmosphere, and improve ecological situation.

3. It is the first time when MHP is recommended to use to recover waste heat from cooling towers of real enterprise PS KSP Steel LLP (Pavlodar) in the Republic of Kazakhstan.

\section{References}

[1] D. Ray, D. McMichael, Heat pumps (Energoizdat, 1982)

[2] A.P. Burdukov, Yu.M. Petin, Heat pumps for Russia: technology of use of geothermal and waste heat by industrial enterprises, Equipment, Developments, Technologies 7, 07, 27-32 (2007)

[3] D.N. Devyanin, S.I. Pisshikov, Yu.N. Sokolov, Development and test of a laboratory stand for approbation of heat pump plants for power industry at CHPP-28 Mosenergo OJSC, News of heat supply 1, 86-93 (2000)

[4] G. Heinrich, et al., Heat pump installations for heating and hot water supply (Stroyizdat, 1985) 
[5] Yu.M. Petin, The decade of heat pump production experience at Energia CJSC, Energy policy 3, 28$33(2001)$

[6] D.G. Zakirov, Utilization of secondary energy resources and the use of renewable energy sources using heat pumps is the main way of burning the energy intensity of production, Thermal engineering, 5 (2002)

[7] E. Bubyalis, K. Marcinauskas, P. Shkema, Opportunities and prospects for the use of heat pumps in the production of low-grade heat. Indastrial power engineering 22, 3 (2000)

[8] A.B. Baranenko, L.S. Timofeevsky, A.G. Dolotov, A.I. Popiov, Absorption Heat Converters: monograph (Saint Petersburg, 2005)

[9] Jian Sun, Lin Fu, Fangtian Sun, Shigang Zhang, Experimental study on a project with CHP system basing on absorption cycles, Applied Thermal Engineering 73, 1, 732-738 (2014)

[10] S. Jian, F. Lin, Zh. Shigang, Experimental study of heat exchanger basing on absorption cycle for CHP system. Applied Thermal Engineering, 102, $1280-1286$ (2016)

[11] H. Tianle, X. Xiaoyun, J. Yi, Simulation research on a variable-lift absorption cycle and its application in waste heat recovery of combined heat and power system, Energy 140, 912-921 (2017)

[12] Yu.M. Petin, S.N. Shamanayev, Ye.V. Oparin, B.S. Golodnikov, Ways of hot water supply and ways of heating thereby, RF Patent no. 2454608 (2012)

[13] X. Xiaoyun, J. Yi, Absorption heat exchangers for long-distance heat transportation, Energy 141, 2242-2250 (2017)

[14] H.S. Zhang, H.B. Zhao, Z.L. Li, Performance analysis of the coal-fired power plant with combined heat and power (CHP) based on absorption heat pumps, Journal of the Power Institute 89, 70-80 (2016)

[15] A.Sh. Alimgazin, Yu.M. Petin, S.G. Alimgazina, A.Ye. Bakhtiayrov, Heat pump plant for heating and hot water supply, KZ Patent no. 1843 (2015)

[16] I.A. Sultanguzin, T. Shomova, P. Shomov, V. Dostovalov, The use of heat pumps in gas processing plants, Abstracts and reports of the XV Minsk International Forum on Heat and Mass Transfer 3, 420-424 (2016)

[17] I.A. Sultanguzin, T. Shomova, P. Shomov, The use of heat pumps in gas processing enterprises: experience and prospects, Plumbing, Heating, Air conditioning, 5, 48-51 (2015)

[18] A. Fedyukhin, I. Sultanguzin, S.Kurzanov, R. Belov, A. Bakulin, T. Shomova, The use of applied software to solve the problems of industrial heat power: a training manual (Moscow: MEI Publishing House, 2016)

[19] A.Sh. Alimgazin, S.G. Alimgazina, K.S. Omarov, A.Ye. Bakhtiyarov, Heat pump for head and cold supply, KZ Patent no. 2289 (2017).
[20] A.Sh. Alimgazin, S.G. Alimgazina, Y.M. Petin, Application of new generation heat pump technologies using alternative energy sources to generate additional heat energy a the heat power plants-2 in Astana city, IX Minsk International Seminar Heat Pipes, Heat Pumps, Refrigerators, Power Sourses, Minsk, Belarus, 230-235 (2015)

[21] A.Sh. Alimgazin, A.N. Berguzinov, Application of Green Heating technology for power supply of the Energy Research Center facility of the international exhibition EXPO-2017, Herald of S.Toraighyrov PSU, a series of Power 1, 21-28 (2017)

[22] A.Sh. Alimgazin, S.G. Alimgazina, A.S. Sharypov, S.Ye. Bakhtiyarova, Commercialization of the modular heat pump for recovering of low-grade waste heat of technical water supply system at enterprises, Volume of the IV International Conference ICITE Industrial technologies and engineering, Shymkent (2017)

[23] A.Sh. Alimgazin, S.G. AlimgazinA, Opportunity to use power-saving heat pumps using alternative sources of power at Aksu Ferroalloy Plant branch of TNK Kazchrome JSC. Herald S.Toraighyrov PSU, Energy series 4, 35-38 (2019) 